DOI: 10.12957/demetra.2018.33425

\title{
Acesso à frutas e hortaliças em áreas periféricas da região metropolitana de São Paulo
}

\section{Access to fruits and vegetables in the peripheral areas of the metropolitan region of São Paulo}

Mariana Tarricone Garcial

Jessica Vaz Franco ${ }^{1}$

Christiane Gasparini Araújo Costal

Cláudia Maria Bógus'

\footnotetext{
1 Universidade de São Paulo, Faculdade de Saúde Pública, Departamento de Política, Gestão e Saúde, Programa de Pós-graduação em Saúde Pública. São Paulo, SP, Brasil.

Fonte de financiamento: FAPESP $n^{0}$ 2011/23.187-3.

Correspondência / Correspondence

Jessica Vaz Franco

Universidade de São Paulo, Faculdade de Saúde Pública, Departamento de Política, Gestão e Saúde. Av. Doutor Arnaldo, 715 - CEP 01246-904 - São Paulo, SP, Brasil

E-mail: jessicavazfranco@usp.br
}

\section{Resumo}

A ausência de ambientes alimentares favoráveis constitui-se em um obstáculo à adoção de práticas alimentares saudáveis. Com o objetivo de descrever práticas de aquisição de frutas e hortaliças de moradores de áreas periféricas da região metropolitana de São Paulo e como percebem o acesso a estes alimentos, foi realizado um estudo descritivo no município de Embu das Artes, São Paulo. Foram conduzidas entrevistas com 47 indivíduos. Os principais locais de aquisição de frutas e hortaliças eram feiraslivres e sacolões. Da análise das entrevistas semiestruturadas identificou-se os seguintes temas principais: disponibilidade de frutas e hortaliças, distância entre o domicílio e os locais de compra, variedade dos alimentos, qualidade dos alimentos e preços dos alimentos. Essa análise revelou o abastecimento insuficiente de frutas e hortaliças. Os relatos que manifestaram percepções positivas em relação à disponibilidade e qualidade de frutas e hortaliças foram daqueles que moravam ou trabalhavam próximos a feiras-livres e sacolões. A alimentação adequada e saudável foi associada a preços altos, ainda que os preços praticados nas feiras-livres tivessem apresentado percepções positivas. Este estudo mostrou que a população que reside próxima a feiras-livres e sacolões utiliza-os com frequência para a compra de frutas e hortaliças. Assim, nota-se a importância destes estabelecimentos típicos de comercialização de alimentos saudáveis distribuídos nos territórios.

Palavras-chave: Segurança Alimentar e Nutricional. Abastecimento de Alimentos. Política Nutricional. Hábitos Alimentares. Meio Ambiente e Saúde Pública. 


\section{Abstract}

The absence of favorable food environments constitutes an obstacle to the adoption of healthy food practices. A qualitative and quantitative study was carried out in the city of Embu das Artes, State of São Paulo, Brazil, in order to describe the fruit and vegetable purchasing practices of the inhabitants living in the peripheral areas of São Paulo metropolitan region and how they perceive the access to these foods. In total, 47 individuals were interviewed. The main fruit and vegetable retailers were open-air markets and in fruit and vegetable stands. From the analysis of semi-structured interviews, the following main themes were identified: fruit and vegetable availability, distance between home and retailers, food variety, food quality and food prices. This analysis revealed the insufficient supply of fruits and vegetables. Respondents who lived or worked near open-air markets and fruit and vegetable stands showed and declared their positive perceptions regarding availability and quality of fruits and vegetables. Adequate and healthy food was associated with high prices, although the prices in open-air markets generated positive perceptions. This study showed that the population that lives close to open-air markets and fruit and vegetable stands usually go to these places to buy fruits and vegetables. Thus, one can notice the importance of such traditional establishments that sell healthy foods and are located in these regions.

Keywords: Food and Nutrition Security. Food Supply. Nutrition Policy. Feeding Behavior. Environment and Public Health.

\section{Introdução}

Nos últimos anos, os brasileiros têm apresentado crescente diminuição no consumo de alimentos tradicionais e, em contrapartida, um considerável aumento no consumo de produtos ultraprocessados. ${ }^{1}$ Além deste padrão alimentar estar relacionado ao aumento da incidência de obesidade e de doenças crônicas não transmissíveis (DCNT), acarreta evidentes prejuízos à cultura alimentar e à comensalidade. ${ }^{2}$ Dado que o comportamento e o estilo de vida dos indivíduos e grupos sociais são fortemente determinados pelo ambiente físico, socioeconômico e cultural em que vivem, a ausência de ambientes alimentares favoráveis constitui-se um obstáculo à adoção de práticas alimentares saudáveis. ${ }^{3}$

Há evidências de que ambientes alimentares de regiões socioeconomicamente desfavorecidas são menos saudáveis em relação à disponibilidade de frutas e hortaliças $(\mathrm{F} \& \mathrm{H})$, qualidade e 
preço dos alimentos, tipos de estabelecimentos, falta de infraestrutura para estocar certos tipos de alimentos, entre outros. ${ }^{4-7}$

O ambiente alimentar, em termos gerais, é um determinante implícito do acesso aos alimentos. Os estudos sobre esta temática que utilizam abordagens subjetivas desempenham papel importante para que haja a implementação de mudanças no ambiente alimentar visando a melhoria na qualidade da alimentação dos indivíduos de forma eficaz. ${ }^{8,9}$

No Brasil, é recente e escassa esta discussão acerca do ambiente alimentar, abordado até agora apenas sob a perspectiva quantitativa., ${ }^{4,10-14}$ A literatura internacional traz evidências de que a percepção dos indivíduos sobre o ambiente alimentar é influenciada por atributos do bairro e por características socioeconômicas e demográficas dos moradores podendo impactar na autoeficácia tanto para alimentação saudável quanto para aquisição de alimentos não saudáveis. ${ }^{9,15,16}$ Assim, o papel que o ambiente alimentar exerce nas escolhas alimentares frente à percepção dos indivíduos pode trazer indicações importantes sobre motivações, atitudes e experiências subjetivas que podem influenciar na aquisição e no consumo de alimentos saudáveis.

As políticas nacionais têm sinalizado a importância de ações nos territórios que facilitem as escolhas alimentares saudáveis pelos indivíduos, na ótica da segurança alimentar e nutricional (SAN) e dos determinantes sociais da saúde., ${ }^{2,17,18}$ Ainda é necessária maior ênfase em relação à qualidade nutricional dos alimentos que a população tem acesso, visto o aumento alarmante do excesso de peso e de outros fatores de risco para DCNT. ${ }^{19}$

O desafio de promover a dimensão nutricional da SAN é importante e complexo, já que a alimentação saudável, além de um dos determinantes da saúde, é culturalmente e socialmente construída e fortemente influenciada pelos determinantes sociais, do acesso, do ambiente e do sistema alimentar. ${ }^{18,20,21}$ Considerando as mudanças negativas - e já relatadas - que vêm ocorrendo na dieta dos brasileiros e o obstáculo às práticas alimentares saudáveis que o ambiente alimentar pode estar desempenhando, especialmente em regiões socioeconomicamente desfavorecidas, este estudo visa contribuir com a literatura referente ao cenário urbano. Neste artigo descrevem-se as práticas de aquisição de $\mathrm{F} \& \mathrm{H}$ de moradores de áreas periféricas da região metropolitana de São Paulo e como eles percebem o acesso a estes alimentos.

\section{Metodologia}

Este trabalho é produto de um projeto maior que investigou a experiência de hortas comunitárias desenvolvidas em Unidades Básicas de Saúde (UBS) e Escolas Municipais no município de Embu das Artes, SP e foi desenvolvida de acordo com as normas vigentes da ética em pesquisas de saúde (OF.COEP/056/12). 


\section{Local de estudo}

O município de Embu das Artes, localizado na Região Metropolitana de São Paulo, possui aproximadamente 240 mil habitantes, todos residentes em áreas urbanas. ${ }^{22}$ Foram compreendidas por este estudo as regiões adstritas a quatro Unidades Básicas de Saúde (UBS) - Santa Emília, Nossa Senhora de Fátima, Jardim Independência e São Luiz - que possuíam hortas comunitárias, que também eram as mais densas em população e mais próximas à cidade de São Paulo, enquadrandose em um contexto de periferia da região metropolitana de São Paulo. Segundo o Centro de Estudos e Pesquisas "Dr. João Amorim" - CEJAM, organização social que realiza a gestão de UBS do município, o número de habitantes atendidos pelas UBS deste estudo são: Santa Emília- 23.456; Nossa Senhora de Fátima- 21.091; Jardim Independência- 19.666; São Luiz- 13.318.

\section{Coleta de dados}

A coleta de dados ocorreu no mês de julho de 2013. Foi realizada por uma equipe de estudantes de graduação e pós-graduação devidamente treinadas.

A Secretaria Municipal de Saúde forneceu os mapas dos territórios adstritos das quatro UBS onde eram desenvolvidas as hortas comunitárias. Mediante consulta junto aos funcionários das UBS (gerentes e agentes comunitários de saúde - ACS) verificou-se quais áreas correspondiam aos territórios de cada uma.

Os sujeitos convidados a participar da pesquisa foram moradores dessas quatro regiões citadas. Foram conduzidas entrevistas semiestruturadas e preenchido questionário sociodemográfico junto a eles. O roteiro de entrevista era composto de 13 questões abertas a respeito dos hábitos de compra de F\&H e percepções em relação ao preço, qualidade, variedade e disponibilidade destes alimentos nos entornos da residência.

A amostra da pesquisa foi realizada por conveniência e não buscou ser estatisticamente representativa da população da região ou do município estudado. No total, foram localizados 49 setores censitários (SC) quando somadas as quatro regiões compreendidas pelo estudo e almejouse entrevistar um morador de cada SC percorrido. As exigências para compor a amostra foram: residir naquele $\mathrm{SC}$, ser maior de 18 anos e ser um dos responsáveis pela alimentação da família.

Os entrevistados foram esclarecidos quanto ao objetivo geral do estudo e forneceram o consentimento livre e esclarecido para sua participação. 


\section{Análise dos dados}

Os questionários sociodemográficos foram digitados com auxílio do programa Epi InfoTM (Centers for Disease Control and Prevention, Atlanta, USA). Em seguida, o banco de dados foi transferido para o pacote estatístico SPSS (IBM, New York, USA) para edição e análise.

Os materiais resultantes das entrevistas semiestruturadas individuais (gravações em áudio e anotações) foram organizados para compor um banco de dados para análise, realizada com o auxílio do software NVivo10 (QSR International Pty Ltd. Version 10, 2012).

A análise dos relatos foi realizada por meio da análise de conteúdo por duas nutricionistas, pós-graduandas em saúde pública, supervisionadas pela orientadora de ambas. ${ }^{23}$ Consistiu em desmembramento do texto transcrito em categorias, evidenciando os núcleos temáticos, norteados por temas relacionados ao Direito Humano à Alimentação Adequada (DHAA) e à segurança alimentar e nutricional (SAN) e ocorrendo em três etapas: pré-análise - organização e sistematização das ideias, com leitura flutuante e formulação das hipóteses; exploração do material - classificação de categorias e, por fim, o tratamento dos dados obtidos e a interpretação, realizados de forma conjunta pelas pesquisadoras.

\section{Resultados}

As características sociodemográficas dos entrevistados podem ser observadas na Tabela 1. A população entrevistada foi composta, em maior frequência, por mulheres (79\%), na faixa dos 41 a 43 anos de idade, casadas (49\%), ensino médio completo (45\%), que trabalhavam (83\%), empregados com carteira de trabalho assinada (46\%) ou por conta própria (38\%) e renda per capita de 1,4 salário mínimo.

Tabela 1. Características sociodemográficas dos entrevistados, moradores das regiões adstritas a quatro UBS (n=47). Embu das Artes, SP, Brasil, 2013.

\begin{tabular}{lcc}
\hline & $\mathrm{N}$ & $\%$ \\
\hline UBS & & \\
Santa Emília & 16 & 34,0 \\
Nossa Senhora de Fátima & 12 & 25,5 \\
Jardim Independência & 11 & 23,4 \\
São Luiz & 8 & 17,0 \\
& & continua
\end{tabular}


$\mathrm{N}$

\section{Sexo}

Feminino

37

10

78,7

Masculino

\section{Estado civil}

Solteiro(a)

Casado(a)

23

8

48,9

Separado/Divorciado/Viúvo (a)

\section{Escolaridade}

Nunca estudou/Fundamental incompleto

Médio completo

$\%$

21,3

17,0

19,1

21,3

44,7

14,9
Superior Completo

\section{Condição de atividade}

Não trabalha

Desempregado(a)

Aposentado(a)

Trabalha

83,0

\section{Condição de trabalho $(n=39)$}

Carteira de trabalho assinada

18

46,2

Trabalho temporário ou informal

4

15

10,2

Conta própria

38,5

Outro

Ocupação' $^{1}(\mathbf{n}=39)$

Serviços de saúde

Prestadores de serviço

Profissionais da educação

Trabalhadores domésticos remunerados

10,3

Trabalhadores do comércio

3

7
7,7

18,0
Outros 


\begin{tabular}{lcc}
\hline & $\mathrm{N}$ & $\%$ \\
\hline Beneficiário de Programas Sociais & 3 & 6,4 \\
& Média (IC95\%) & Mediana \\
Idade (anos) & $43,4(38,8-48,0)$ & 41,0 \\
Renda per capita (R\$) & $999,4(730,5-1268,3)$ & 787,5 \\
Renda per capita (salários mínimos) & $1,4(1,0-1,8)$ & 1,1 \\
\hline
\end{tabular}

${ }^{1}$ Serviços de saúde: Agentes comunitários de saúde; Prestadores de serviço: Cabelereiros, costureiras, mecânicos, motoristas e pintores; Profissionais da educação: professores, inspetores de alunos, diretores e merendeiras; Trabalhadores domésticos remunerados: Domésticas, babás e cuidadores; Trabalhadores do comércio: Vendedores, proprietários de lojas e comércios; Outros: Autônomos, bicos, auxiliares administrativos e funcionários públicos com funções não esclarecidas.

Foram entrevistados moradores de 47 dos 49 setores censitários $(95,9 \%)$ identificados pelos profissionais das UBS como parte de seus territórios adstritos, dois SC eram inacessíveis.

Quando foram investigados os locais de aquisição de frutas, observou-se que os moradores as adquiriam em feiras-livres $(39,1 \%)$, sacolões $(37,0 \%)$, supermercados $(19,6 \%)$ e mercados $(4,4 \%)$. Já a aquisição das hortaliças ocorreu em sacolões (42,6\%), feiras-livres (31,9\%), supermercados $(21,3 \%)$ e mercados $(4,3 \%)$.

A distribuição da frequência de aquisição de $\mathrm{F} \& \mathrm{H}$, meio de transporte utilizado e distância de deslocamento segundo locais de aquisição estão apresentados na Tabela 2. Destaca-se a diferença percentual encontrada entre os meios de transporte para a locomoção até as feiras-livres/sacolões quando comparados a outros locais. A grande maioria dos indivíduos vai caminhando às feiraslivres/sacolões (89\%), ou seja, estes locais são próximos de suas residências. Já em relação aos que os adquirem em supermercados, essa proporção cai para $44 \%$ para a aquisição de frutas e $50 \%$ para a aquisição de hortaliças. O inverso ocorre quando se observa o "veículo motorizado próprio". No caso das feiras-livres/sacolões, apenas $6 \%$ dos indivíduos os utilizam. Já em relação às pessoas que os adquirem em supermercados, essa proporção é de $57 \%$ para a aquisição de frutas e $50 \%$ para a aquisição de hortaliças.

Em média, o deslocamento a pé para a compra de frutas foi de 532m (IC 95\% 339m-725m) e a mediana foi de $300 \mathrm{~m}$. Já para as hortaliças o valor foi de 509m (IC 95\% 314m-703m) e a mediana foi de $250 \mathrm{~m}$. 


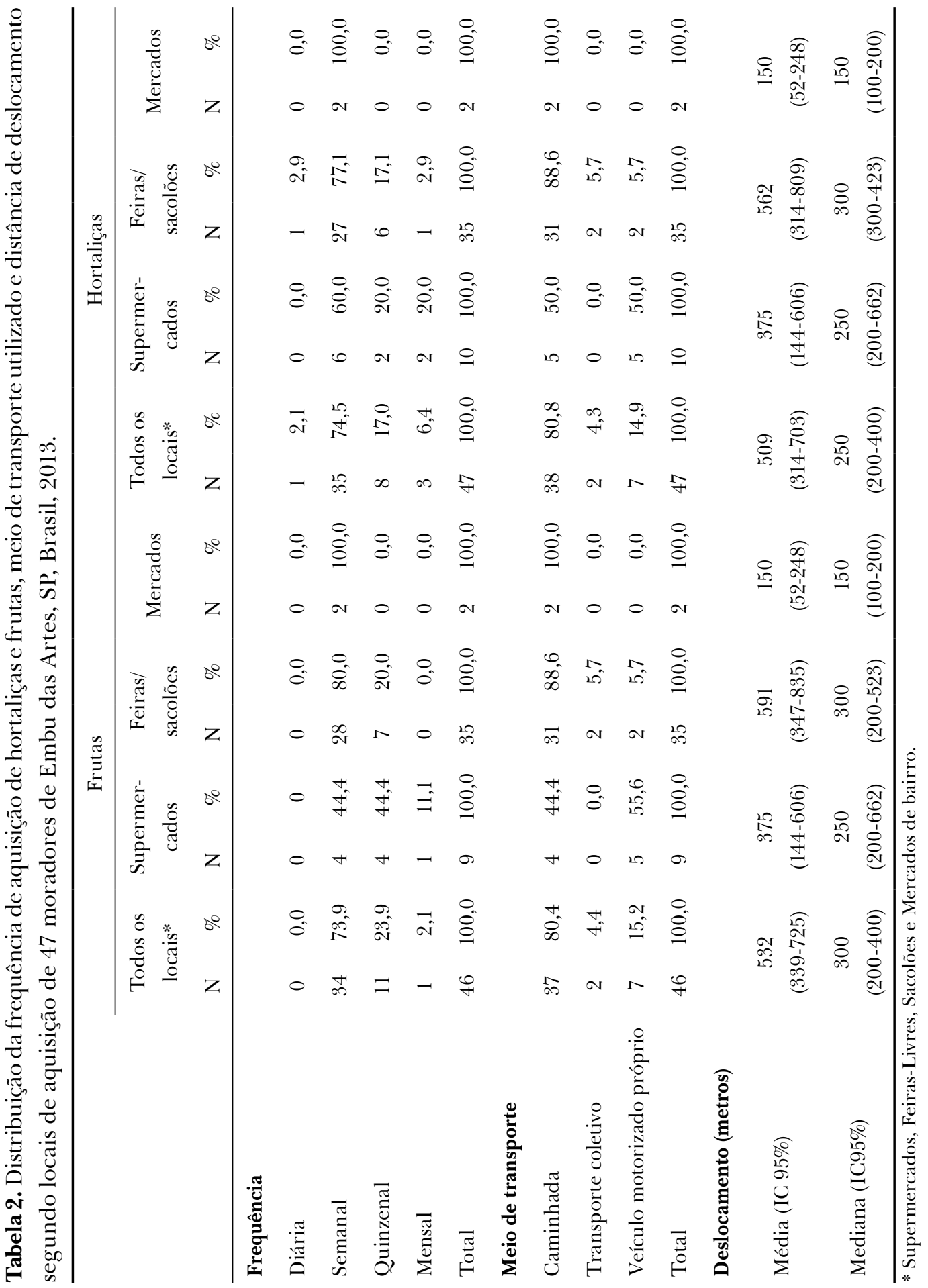


Da análise das entrevistas semiestruturadas foram identificadas as seguintes categorias temáticas principais: disponibilidade de $\mathrm{F} \& \mathrm{H}$, distância entre o domicílio e os locais de compra, variedade dos alimentos, qualidade dos alimentos e preços dos alimentos.

\section{Disponibilidade de F\&H}

Como subcategorias foram identificadas: Insuficiência de estabelecimentos que ofertem $\mathrm{F} \& \mathrm{H}$; Abastecimento insuficiente de F\&H; Encerramento de feiras-livres na região e; Satisfação por aqueles que residiam próximos a feiras-livres e sacolões. As falas selecionadas para ilustrar as percepções dos moradores em relação à disponibilidade de frutas e hortaliças são apresentadas no Quadro 1.

A insuficiência de locais para aquisição de $\mathrm{F} \& \mathrm{H}$, como feiras-livres e sacolóes, foi relatada pela maioria dos entrevistados, além do abastecimento insuficiente de $\mathrm{F} \& \mathrm{H}$, o que determinava a falta destes alimentos durante a semana. A pouca quantidade de estabelecimentos que comercializassem alimentos frescos foi considerada um obstáculo à realização de práticas alimentares saudáveis.

Em uma das regiões os moradores referiram que dois supermercados controlavam o comércio de F\&H, o que levou ao encerramento das atividades das feiras livres na região. Entre os entrevistados que possuíam feiras livres e sacolões próximos de suas residências, a manifestação de percepções positivas foi frequente, assim como no caso de padarias e açougues.

Alguns moradores citaram possíveis maneiras de solucionar o problema de abastecimento local de F\&H, como a implementação de sacolões públicos, de novas feiras livres ou estabelecimentos que priorizassem a venda de F\&H e a continuidade e expansão dos projetos de hortas comunitárias nas UBS.

\section{Distância entre o domicílio e os locais de compra}

Teve-se como subcategorias: Poucas feiras-livres e sacolões próximos das residências e Deslocamento para locais mais distantes em busca de alimentos com melhor qualidade. O Quadro 1 apresenta as falas que demonstram as percepções dos moradores em relação à distância entre o domicílio e os locais de compra.

Os entrevistados relataram muita insatisfação em relação à distância até locais para a compra de alimentos, principalmente $\mathrm{F} \& \mathrm{H}$, com qualidade, variedade e preço considerados satisfatórios. A maioria dos que manifestaram percepções positivas em relação a esta categoria relataram a proximidade com supermercados e estabelecimentos especializados, como sacolões. 
Alguns moradores relataram que o fato de não possuírem um automóvel próprio dificultava a realização das compras, uma vez que os estabelecimentos não realizavam entrega em domicílio. A realização da compra nas proximidades da residência muitas vezes fazia-se por necessidade.

\section{Variedade dos alimentos}

O que se destacou como subcategoria foi "Pouca variedade de F\&H é encontrada na região". As falas escolhidas para exemplificar as percepções dos moradores em relação à variedade dos alimentos são apresentadas no Quadro 1.

A insatisfação em relação à falta de variedade de F\&H também foi relatada pelos entrevistados. As hortaliças, de modo geral, foram mais criticadas em relação à variedade em comparação com as frutas. Os entrevistados compararam os bairros que residiam com bairros de maior poder aquisitivo, nos quais existiria maior variedade de estabelecimentos e diversidade de alimentos saudáveis. 
Quadro 1. Falas dos moradores da região segundo categorias temáticas principais. Embu das Artes, SP, Brasil, 2013.

\section{Disponibilidade de frutas e hortaliças}

As feiras, elas cada vez vão reduzindo [...] Na verdade, eu acredito que não só aqui, mas em várias regiões, com certeza deve ter diminuído porque aqui no nosso bairro tinha feira e hoje nós não temos mais (Morador da região Santa Emília).

"Entrevistadora: [...] que sugestões você daria ao governo ou prefeitura para melhorar a alimentação da região em que você vive?

Entrevistada: Eu acho que mais hortas comunitárias, apesar que não é só o governo que tem que se sensibilizar, eu acho que a população principalmente porque a gente tinha aqui a horta comunitária e a gente convidava os pacientes que são aqui da UBS Independência para participar, e eles não participavam" (Moradora da Jardim Independência).

“[...] Em São Paulo não tem aquele sacolão da prefeitura? Aqui no Embu das Artes precisava ter também, dar mais oportunidade às pessoas que tem menos condições de comprar as coisas de ter uma alimentação boa (Moradora da região Santa Emília).

\section{Distância entre o domicílio e os locais de compra}

"São poucas opções de frutas, verduras, a gente tem que andar, por exemplo, uns dez minutos para comprar e às vezes dificulta porque a gente tem que fazer alguma coisa em casa e não dá para ir rapidinho e voltar”. (Moradora da região Jardim Independência).

"Perto da minha casa tem um sacolão, que sempre tem tudo fresquinho" (Moradora da região Nossa Senhora de Fátima).

"Aqui você só tem uma opção e é obrigado a ir nela [...]tendo carro você escolhe o local né?! Agora quando não tem um transporte, tem que ir justamente naquele lugar por ser mais próximo da sua casa”. (Morador da região Santa Emília).

\section{Variedade dos alimentos}

"[...] Aqui tinha que ser mais rico em variedade, é só o tradicional que tem como: alface, repolho, brócolis, e ainda assim de má qualidade, que parece o resto que sobrou... aí tem que sair daqui para outros lugares para poder comprar coisas melhores e mais variedades"(Moradora da região Jardim Independência).

"[...] Algumas variedades em relação a hortaliças que falta, então às vezes preciso ir no município vizinho para conseguir encontrar diversidade maior” (Moradora da Região Santa Emília).

"Eu acho que deveria ter mais variedades de locais e dos alimentos, por exemplo, quando a gente vai num lugar mais longe, o supermercado que a gente vê que a nossa classe não vai, tem mais variedade de alimentos do que no nosso próprio bairro" (Moradora da Região Independência). 


\section{Qualidade dos alimentos}

Foram identificadas como subcategoria: Satisfação quanto aos sacolões e feiras-livres e Qualidade de F\&H satisfatória nas datas de fornecimento para os supermercados. O Quadro 2 retrata as falas que exemplificam as percepções dos moradores em relação à qualidade dos alimentos.

Percepções positivas em relação à qualidade dos alimentos foram frequentes, principalmente entre aqueles moradores que residiam próximos a feiras livres e sacolóes. Foi relatado que nos dias em que ocorria o abastecimento de $\mathrm{F} \& \mathrm{H}$ nos supermercados os preços eram mais atrativos e a qualidade era aceitável. No entanto, ao longo dos demais dias, os alimentos se deterioravam, sem haver reposição.

Alguns moradores referiram deixar de comprar $\mathrm{F} \& \mathrm{H}$ devido à qualidade insatisfatória. Um morador mencionou a existência de locais que comercializam $\mathrm{F} \& \mathrm{H}$ a preços baixos e relatou sua preocupação com a higiene do local e com a qualidade dos alimentos.

\section{Preços dos alimentos}

Como subcategorias, destacaram-se: Satisfação quanto às feiras-livres; Críticas aos supermercados (falta de "concorrência”); Alimentação saudável associada a preços altos e; Preços altos nos estabelecimentos mais próximos. As falas selecionadas para apontar as percepções dos moradores em relação ao preço dos alimentos são apresentadas no Quadro 2.

O preço dos alimentos em geral foi um dos temas mais recorrentes. Alguns moradores, inclusive, deixavam de comprar alimentos devido ao preço. Os locais mais aceitáveis em relação aos preços foram as feiras livres, porém ocorriam com pouca frequência. Muitos entrevistados relataram que a falta de "concorrência" no comércio de alimentos saudáveis levou à prática dos preços altos.

Alimentos como F\&H, alimentos orgânicos, pescados, laticínios, feijão e carnes foram associados a preços altos, muitas vezes determinando piores escolhas alimentares. Houve o relato de uma moradora que associou a horta comunitária da UBS de sua região com a garantia do acesso a hortaliças de qualidade e sem custo. 
Quadro 2. Falas dos moradores da região segundo categorias temáticas principais. Embu das Artes, SP, Brasil, 2013.

\section{Qualidade dos alimentos}

"[...]No sacolão tem coisas boas, e a gente quando compra se sente bem porque são tudo boas" (Morador da Região São Luiz).

"Sei que tem coisa boa de quarta-feira que eles vão ao Ceasa, mas só de quarta-feira" (Moradora da Região Santa Emília).

"[...]Não temos opção para comprar, pra a gente escolher o que quer, você procura uma batatinha não tem, só coisas velhas já passadas, não sei de quanto tempo” (Morador da Região Santa Emília).

"[...]A gente percebe as vezes que falta um pouco de cuidado no armazenamento destes produtos e que as condições de higiene não estão muito adequadas para estarem ali, mas a gente compra porque precisa" (Morador da Região Jardim Independência).

\section{Preços dos alimentos}

"Acho que está muito caro, não está compensando mais fazer [compras] muito próximo de casa, então procuramos sempre ir aonde tem mais ofertas, vamos cada vez mais longe" (Moradora da região Jardim Independência).

"É muito caro [FEHH], então a gente acaba comprando uma vez por semana na feira de domingo que está mais em conta, porque no sacolão daqui da região está muito caro". (Moradora da região Jardim Independência).

"A variação de preços aqui, por existir poucos mercados na área [...] Ficou manipulado só na mão de dois, de um... Então você se sujeita a comprar só naquele lugar eautomaticamente tem que pagar o preço que querem, não existe concorrente aqui”. (Morador da região Jardim Independência). "Acho que eles deveriam, tipo, estabelecer um preço né, todos os comerciantes, tipo uma tabela de preço, ah como é que eu posso falar, geralmente nas farmácias, em sua maioria os preços são iguais, a diferença é pouca, aqui por não ter muita opção, o pessoal mete a faca, entendeu?" (Moradora da região Jardim Independência)

"A dificuldade é por conta dos preços né, quando a gente ainda mexia com a horta, pelo menos a gente sempre tinha verdurinha, mas agora eu não tenho, em casa não tenho nem tempo e nem espaço" (Moradora da Região Independência). 


\section{Facilitadores e obstáculos a práticas alimentares saudáveis}

Algumas percepções dos participantes puderam ser reconhecidas como facilitadores ou obstáculos à realização de práticas alimentares saudáveis (Figura 1). Como facilitadores, puderam ser identificados o fato de residir próximo às feiras livres e sacolóes e a possibilidade de adquirir F\&H na data de fornecimento para os supermercados. Já como obstáculos, foram identificados os preços altos associados à alimentação saudável, a pouca variedade disponível de F\&H, a insuficiência de feiras-livres e sacolões e o abastecimento insuficiente de F\&H.

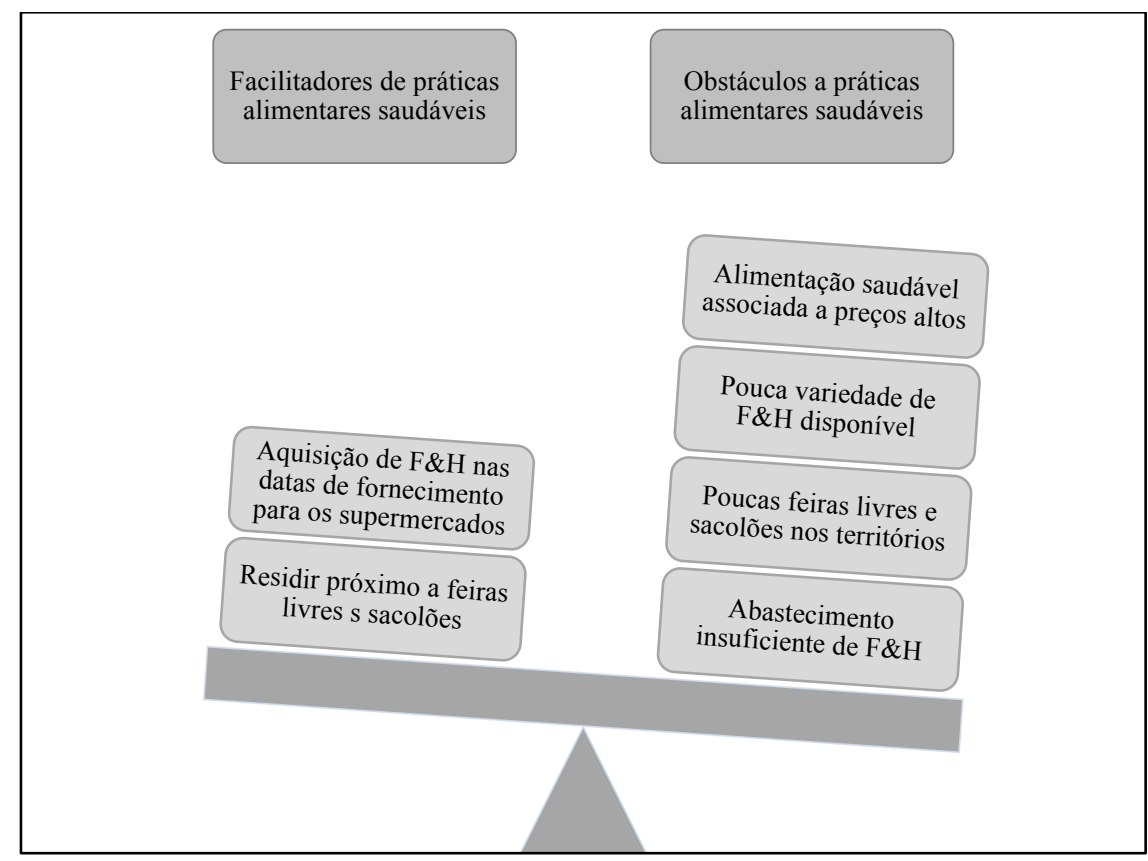

Figura 1. Facilitadores e obstáculos para a realização de práticas alimentares saudáveis de 47 moradores de territórios adstritos de 4 Unidades Básicas de Saúde em Embu das Artes, SP, Brasil, 2013. 


\section{Discussão}

Neste trabalho, um dos pioneiros no Brasil na apresentação de dados qualitativos sobre a percepção dos indivíduos em relação ao ambiente alimentar da região onde vivem, a população entrevistada foi, em sua maior frequência, composta por mulheres economicamente ativas de classe média. É interessante ressaltar o gênero da maioria dos entrevistados (79\% de mulheres) pelas singularidades na relação que estabelecem com a cidade.

As mulheres, em geral, são responsáveis pela aquisição e preparação dos alimentos para a família e, também, as principais envolvidas na educação das crianças e têm papel estratégico na promoção de hábitos alimentares. ${ }^{24}$ Elas expressam uma sensibilidade particular quanto aos aspectos que interferem e determinam as necessidades sociais e de saúde, incluídas as relacionadas com a alimentação, no desenvolvimento de suas tarefas familiares, domésticas e profissionais.

Os relatos que manifestaram percepções positivas em relação à disponibilidade, variedade e qualidade de F\&H foram daqueles que moravam ou trabalhavam próximo aos estabelecimentos que vendiam estes alimentos. Observou-se que a forma de locomoção mais utilizada para a aquisição de F\&H foi a caminhada, portanto, a existência de um sacolão ou feira livre próximo da residência pode contribuir para a utilização desses locais.

Estudos têm mostrado que, apesar de o custo dos alimentos ser uma importante barreira para o consumo, a localização dos estabelecimentos também pode impedir o acesso à alimentação adequada e saudável (AAS).$^{25}$ Vedovato et al., em estudo realizado em Santos-SP, observaram que os fatos de haver uma feira livre ou um sacolão próximo da residência e de a caminhada ser o principal meio de transporte para compra de alimentos, contribuíram para a associação entre as percepções positivas sobre a disponibilidade de F\&H na vizinhança e padrões de compra de alimentos saudáveis. ${ }^{10}$

Outros estudos demonstraram associação positiva entre ambientes favoráveis para a venda de alimentos saudáveis e a boa percepção em relação à qualidade, variedade, preço e consumo, que são fatores decisivos para a escolha e compra deste grupo alimentar. ${ }^{25,26}$ Desta forma, destaca-se a importância da existência de estabelecimentos que comercializem alimentos saudáveis em áreas residenciais, principalmente nos bairros onde os moradores fazem muitos trajetos a pé, já que a pouca quantidade destes pode dificultar o acesso à AAS. ${ }^{27}$

Sabe-se que entre a oferta, a aquisição e o consumo de alimentos saudáveis existem processos complexos que envolvem o poder de compra, os hábitos e as preferências alimentares, além da educação nutricional, habilidades culinárias, tempo disponível para preparo, entre outros. Para que todos os indivíduos saibam identificar e ter capacidade de adotar opções saudáveis de alimentação é necessário, entre outros aspectos, níveis mínimos de renda e acesso universal a conhecimentos básicos sobre a relação entre alimentação e saúde. ${ }^{28}$ Todos estes fatores devem ser considerados nas intervenções que buscam a promoção da AAS, inclusive no ambiente alimentar. 
Neste estudo, os entrevistados associaram a AAS a preços altos e bairros de maior poder aquisitivo a uma maior variedade de alimentos saudáveis, em comparação aos bairros que residiam. Os mecanismos socioeconômicos de estratificação e distribuição desigual de riquezas, associados à falta de força política e organizativa da população para reagir a isso, constituem determinantes das iniquidades em saúde, afetando as comunidades periféricas e impondo a situação de vulnerabilidade social a alguns grupos sociais. ${ }^{29}$ Em Belo Horizonte/MG, no estudo realizado por Pessoa et al., ${ }^{11}$ foi observado que quanto maior a renda média do bairro, maior era o número de estabelecimentos que comercializavam alimentos de todos os tipos e essa população apresentou o maior consumo de F\&H.

No presente estudo, houve relatos sobre a diminuição do número de feiras livres devido ao surgimento de supermercados nestes bairros da periferia. De fato, tem havido uma alteração na dinâmica do varejo urbano, em especial em relação à oferta de $\mathrm{F} \& \mathrm{H}$. As feiras-livres, importantes estabelecimentos varejistas para aquisição de $\mathrm{F} \& \mathrm{H}$, vêm perdendo sua participação na venda destes produtos para sacolóes e supermercados e, principalmente, para as grandes redes supermercadistas. ${ }^{30}$

Wegner $^{31}$ destaca que a falta de mecanismos de regulação pública para o abastecimento de F\&H constitui um obstáculo à efetivação do DHAA. As tendências de concentração no comércio varejista se intensificaram na década de 1990, com numerosas fusões e aquisições de empresas, entrada de grandes grupos internacionais e expansão de cadeias varejistas pré-existentes, juntamente com o não comprometimento do poder público com o abastecimento, permitindo que os supermercados se tornassem dominantes na distribuição de alimentos, inclusive $\mathrm{F} \& \mathrm{H}$, para a população. ${ }^{31,32}$

Atualmente, diversos supermercados são dirigidos ao público de baixa renda e as grandes redes de supermercado estão presentes nos bairros periféricos das grandes cidades por meio da instalação de lojas menores com diferentes bandeiras..$^{33,34}$

Os resultados deste estudo sinalizam importantes relações entre as características do abastecimento de alimentos no território e a aquisição de F\&H. O abastecimento é um tema integrador, que exprime os vínculos entre a produção e o consumo alimentar e necessita de um papel maior do Estado visando o acesso a alimentos saudáveis. Nabuco \& Porto ${ }^{35}$ consideram que o mercado impõe distorções na distribuição e na comercialização de alimentos, portanto cabe ao Estado intervir na cadeia agroalimentar para permitir que setores excluídos tenham acesso à alimentação em quantidade e qualidade compatíveis com as suas necessidades diárias. No contexto de uma sociedade capitalista, onde os alimentos são vistos como mercadoria, a oferta de alimentos responde à lógica da sociedade de consumo, com estratégias de marketing sedutoras, massificação do consumo e tendência ao consumismo. 
Os entrevistados referiram que as feiras-livres e sacolões eram os principais locais para aquisição de $\mathrm{F} \& \mathrm{H}$, seguidos dos supermercados, resultado que difere da literatura internacional onde relata que os supermercados são os estabelecimentos que disponibilizam maior quantidade e variedade de alimentos saudáveis em comparação com os mercados de pequenas dimensões. ${ }^{5,7}$ No Brasil, Vedovato et al. ${ }^{10}$ observaram que o hábito de comprar F\&H em feiras-livres ou sacolões foi associado com um aumento em duas vezes na chance de adquirir alimentos minimamente processados em comparação com as famílias que geralmente compram F\&H em supermercados. Vantagens oferecidas por supermercados na comercialização de $\mathrm{F} \& \mathrm{H}$ foram relatadas em nosso estudo. Entretanto, ao mesmo tempo em que são convenientes, os supermercados também disponibilizam muitas variedades de ultraprocessados a preços reduzidos que podem incentivar ao maior consumo destes.

É fundamental compreender que as abordagens individuais para a promoção da AAS, ainda que importantes, não são suficientes para enfrentar essa importante questão de saúde pública. São necessários vontade política, empoderamento do consumidor e atuação da sociedade civil organizada para cobrar a implementação de políticas que priorizam a saúde pública frente aos interesses dos agentes econômicos.

Os resultados deste estudo devem ser interpretados à luz de algumas limitações. O fato de as quatro regiões estudadas serem vizinhas e muito semelhantes nas características sociodemográficas não permitiu realizar comparações entre elas. Em decorrência do método de seleção dos entrevistados, pode ter havido uma tendência em selecionar perfis de indivíduos semelhantes, sendo a maioria da população estudada composta de mulheres, casadas e economicamente ativas. Também, vale destacar que 28\% dos entrevistados trabalhavam como ACS nas UBS da região em que residiam. Portanto, pode ser que esse grupo tenha apresentado percepções mais críticas em relação ao ambiente alimentar por serem profissionais da saúde. Por fim, a amostra de 47 indivíduos não possibilitou análises estatísticas mais complexas.

\section{Conclusão}

Este estudo revelou questões relevantes frente ao abastecimento insuficiente e a pouca variedade disponível de frutas e hortaliças $(\mathrm{F} \& \mathrm{H})$ em territórios deste tipo, destacando a insuficiência de estabelecimentos que os comercializem com qualidade. A população que reside próxima a feiras-livres e sacolões utiliza-os com frequência para a compra de F\&H, tanto pela melhor qualidade quanto pelo menor preço praticado. Assim, nota-se a importância da existência destes estabelecimentos típicos de comercialização de alimentos saudáveis em regiões residenciais, visto que a sua ausência pode determinar a baixa aquisição de F\&H. A implantação de comércios públicos de abastecimento acessíveis, como varejões públicos e feiras-livres aos finais de semana ou 
noturnas, como horário alternativo, pode se constituir em estratégia fundamental para o acesso à alimentação adequada e saudável (AAS), principalmente por parte da população de baixa renda.

\section{Colaboradoras}

Garcia MT contribuiu na concepção e desenho, análise e interpretação dos dados, revisão e aprovação da versão final do artigo. Franco JV contribuiu na concepção e desenho, análise e interpretação dos dados, revisão e aprovação da versão final do artigo. Costa CGA contribuiu na concepção e desenho, análise e interpretação dos dados. Bógus CM contribuiu na concepção e desenho, análise e interpretação dos dados, revisão e aprovação da versão final do artigo.

Conflito de interesses: Os autores declaram não haver conflitos de interesse.

\section{Referências}

1. Martins AP, Levy RB, Claro RM, Moubarac JC, Monteiro CA. Participação crescente de produtos ultraprocessados na dieta brasileira (1987-2009). Rev Saúde Pública. 2013; 47(4):656-665.

2. Brasil. Ministério da Saúde. Secretaria de Atenção à Saúde. Departamento de Atenção Básica. Guia alimentar para a população brasileira. 2. ed. Brasília: Ministério da Saúde; 2014.

3. Barreto SM, Pinheiro ARO, Sichieri R, Monteiro CA, Batista Filho M, Schimidt MI, et al. Análise da estratégia global para alimentação, atividade física e saúde, da Organização Mundial da Saúde. Epidemiol Serv Saúde. 2005; 14(1):41-68.

4. Duran AC, Diez Roux AV, Latorre MR, Jaime PC. Neighborhood socioeconomic characteristics and differences in the availability of healthy food stores and restaurants in São Paulo, Brazil. Health \& Place. 2013; 23:39-47.

5. Andreyeva T, Middleton AE, Long MW, Luedicke J, Schwartz MB. Food retailer practices, attitudes and beliefs about the supply of healthy foods. Public Health Nutrition. 2011; 14(6):1024-1031.

6. Ball K, Timperio A, Crawford D. Neighborhood socioeconomic inequalities in food access and affordability. Health \& Place. 2009; 15(2):578-585.

7. Latham J, Moffat T. Determinants of variation in food cost and availability in two socioeconomically contrasting neighborhoods of Hamilton, Ontario, Canada. Health \& Place. 2007; 13(1):273-287.

8. Flint E, Cummins S, Matthews S. Do perceptions of the neighbourhood food environment predict fruit and vegetable intake in low-income neighbourhoods? Health \& Place. 2014; 24:11-15.

9. Williams LK, Thornton L, Ball K, Crawford D. Is the objective food environment associated with perceptions of the food environment? Public Health Nutrition. 2012; 15(2):291-298.

10. Vedovato GM, Trude AC, Kharmats AY, Martins PA. Degree of food processing of household acquisition patterns in a Brazilian urban area is related to food buying preferences and perceived food environment. Appetite. 2015; 87:296-302. 
11. Pessoa MC, Mendes LL, Caiaffa WT, Malta DC, Velásquez-Meléndez G. Availability of food stores and consumption of fruit, legumes and vegetables in a Brazilian urban area. Nutrición Hospitalaria. 2014; 31(3):1438-1443.

12. Martins PA, Creamm EC, Leite FH, Maron LR, Scagliusi FB, Oliveira MA. Validation of an adapted version of the nutrition environment measurement tool for stores (NEMS-S) in an urban area of Brazil. J Nutr Educ Behav. 2013; 45(6):785-792.

13. Velasquez-Melendez G, Mendes LL, Padez CMP. Built environment and social environment: associations with overweight and obesity in a sample of Brazilian adults. Cad Saúde Pública. 2013; 29(10):1988-1996.

14. Leite FH, Oliveira MA, Cremm EC, Abreu DS, Maron LC, Martins PA. Availability of processed foods in the perimeter of public schools in urban areas. J Pediatri. 2012; 88(4):328-334.

15. Sohi I, Bell BA, Liu J, Battersby SE, Liese AD. Differences in food environment perceptions and spatial attributes of food shopping between residents of low and high food access areas. Nutrition Education and Behavior. 2014; 46(4):241-249.

16. Erinosho TO, Oh AY, Moser RP, Davis KL, Nobeling LC, Yaroch AL. Association between perceived food environment and self-efficacy for fruit and vegetable consumption among US adults, 2007. Prev Chronic Dis. 2012; 9:E10.

17. Castro IRR. Desafios e perspectivas para a promoção da alimentação adequada e saudável no Brasil. Cad Saúde Pública. 2015; 31(1):07-09.

18. Alves KPS, Jaime PC. A Política Nacional de Alimentação e Nutrição e seu diálogo com a Política Nacional de Segurança Alimentar e Nutricional. Ciênc Saúde Coletiva. 2014; 19(11):4331-4340.

19. Brasil. Ministério da Saúde. Secretaria de Vigilância em Saúde. Departamento de Vigilância de Doenças e Agravos não Transmissíveis e Promoção de Saúde. Vigitel Brasil 2014: vigilância de fatores de risco e proteção para doenças crônicas por inquérito telefônico. Brasília: Ministério da Saúde; 2015.

20. Brasil. Conselho Nacional de Segurança Alimentar e Nutricional. GT - Alimentação Adequada e Saudável. Relatório final. Brasília: Consea; 2007.

21. Pinheiro ARO. A alimentação saudável e a promoção da saúde no contexto da segurança alimentar e nutricional. Revista do Centro Brasileiro de Estudos de Saúde: Saúde em Debate. 2005; 29(70):125-139.

22. Instituto Brasileiro de Geografia e Estatística. Censo demográfico 2010: características da população e dos domicílios: resultados do universo. Rio de Janeiro: IBGE; 2011.

23. Franco MLPB. Análise de conteúdo. Brasília: Liber Livro; 2005.

24. Siliprandi EC. A alimentação como um tema político das mulheres. In: Rocha C, Burlandy L, Magalhães R. Segurança Alimentar e Nutricional: perspectivas, aprendizados e desafios para as políticas públicas. Rio de Janeiro: Editora Fiocruz; 2013.

25. Morland K, Wing S, Diez-Roux A, Poole C. Neighborhood characteristics associated with the location of food stores and food service places. Am J Prev Med. 2002; 22(1):23-29.

26. Jaime PC, Duran AC, Sarti FM, Lock K. Investigating environmental determinants of diet, physical activity, and overweight among adults in São Paulo, Brazil. J Urban Health. 2011; 88(3):557-581. 
27. Glanz K, Sallis JF, Saelens BE, Frank LD. Nutrition Environment Measures Survey in stores (NEMS-S): development and evaluation. Am J Prev Med. 2007; 32(4):282-289.

28. Ribeiro CD, Pilla MC. Segurança alimentar e nutricional: interfaces e diminuição de desigualdades sociais. DEMETRA: Alimentação, Nutrição \& Saúde. 2013; 9(1):41-52.

29. Junges JR, Barbiani R. Interfaces entre território, ambiente e saúde na atenção primária: uma leitura bioética. Revista Bioética. 2013; 21(2):207-217.

30. Martins VA, Margarido MA, Bueno CRF. Alteração no perfil de compra de frutas, legumes e verduras nos supermercados e feiras livres na cidade de São Paulo. Informações Econômicas. 2007; 37(2):30-37.

31. Wegner RC. Direito humano à alimentação: marco conceitual e legal para a presença do setor público brasileiro no abastecimento de frutas, legumes e verduras. Segurança Alimentar e Nutricional. 2011; 18(1):73-92.

32. SEBRAE-SP, FIPE. Impacto da expansão das grandes redes de supermercados na atividade dos minimercados e mercearias da região metropolitana de São Paulo. Relatório de Pesquisa [Internet]. São Paulo: SEBRAE-SP; FIPE; 2004. [acesso em: 10 nov. 2014]. Disponível em: https://m.sebrae. com.br/Sebrae/Portal\%20Sebrae/UFs/SP/Pesquisas/minimercado_mercearia.pdf

33. Gaspar MA, Borgato F, Lima IC. Estratégia de atuação em rede de negócios: estudo de caso no pequeno varejo de alimentos. Revista da Micro e Pequena Empresa. 2013; 7(1):03-16.

34. Parente JG. O varejo de alimentos para consumidores de baixa renda no Brasil. São Paulo: FGVEAESP/GVPesquisa; 2008. Relatório de Pesquisa, n. 16.

35. Nabuco MR, Porto SI. Como planejar e executar o abastecimento alimentar municipal. In: Belick W, Maluf RS, organizadores. Abastecimento e segurança alimentar: os limites da liberalização. Campinas: IE/UNICAMP; 2000. p. 209-234.

Recebido: 02 de abril de 2018

Revisado: 22 de maio de 2018

Aceito: 17 de junho de 2018 